Research Article

\title{
Experimental Investigation on the Propagation of Hydraulic Fractures through Coal-Rock Interfaces
}

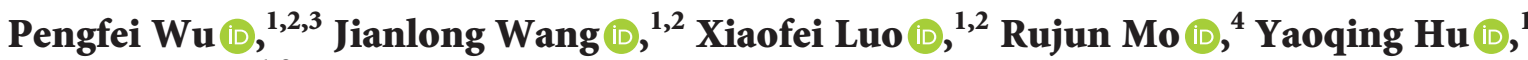 \\ and Wei He $\mathbb{D}^{1,2}$ \\ ${ }^{1}$ Key Laboratory of In-Situ Property-Improving Mining of Ministry of Education, Taiyuan University of Technology, \\ Taiyuan 030024, China \\ ${ }^{2}$ College of Mining Engineering, Taiyuan University of Technology, Taiyuan 030024, China \\ ${ }^{3}$ College of Safety and Emergency Management Engineering, Taiyuan University of Technology, Taiyuan 030024, China \\ ${ }^{4}$ Shaanxi Yan'an Oil and Gas Limited, Xi'an 7100000, China \\ Correspondence should be addressed to Pengfei Wu; wupengfei@tyut.edu.cn
}

Received 11 August 2021; Revised 26 November 2021; Accepted 4 December 2021; Published 22 December 2021

Academic Editor: Ivan Giorgio

Copyright (C) 2021 Pengfei Wu et al. This is an open access article distributed under the Creative Commons Attribution License, which permits unrestricted use, distribution, and reproduction in any medium, provided the original work is properly cited.

\begin{abstract}
Although hydraulic fracturing has been one of the primary stimulation methods for coal-bed methane (CBM) exploration, it is difficult to be applied in soft and low-permeability coal seams due to the instability of wells in such geological structures. In order to solve the problem, an idea of indirect fracturing is proposed, that is, fractures are initiated in stable and hard rocks and then propagated to coal seams in which crack networks can be formed. To verify the feasibility of such an approach, the true triaxial hydraulic fracturing experiments were conducted using two-dimensional and three-dimensional coal-rock combination samples, respectively. This study investigates the fracture patterns, pressure variation, and fracture morphology. The results show that in the process of fracture propagation from sandy mudstones to coals, the strain energy release rate in the sandy mudstones is 10.69 25.53 times greater than that in the coal. When the fracture has a tendency to deflect toward the lower strength coal strata, under the condition of large $K_{2} / K_{1}$, the deflection criterion will be met first and the fracture will deflect and grow into the coal strata. In addition, the complex crack network can be generated when the hydrofracture intersects the coal-rock interface and the fracture pattern is analyzed.
\end{abstract}

\section{Introduction}

Coal-bed methane (CBM) is referred to as the hydrocarbon gas existing in coal strata. As high-quality clean energy, accelerating the development and utilization of CBM resources is of great significance for preventing coal mine gas disasters, increasing the supply of clean energy, and reducing greenhouse gas emissions. Hydraulic fracturing technology has been the main approach for CBM exploitation since its first commercial application in the United States in the 1980s. Taking a comprehensive view of the international CBM drainage cases, the CBM wells [1-4] were mostly distributed in coal seams with a relatively complete structure, high brittleness, good permeability, and high reservoir pressure. However, in soft and low-permeability coal seams, successful cases of CBM extraction using hydraulic fracturing are rarely found [5-9]. Under the action of complex tectonic stress, the overall structure of the coal seam is destroyed, the joints and fissures are developed, and the strength is low. A large number of engineering practices have found that CBM wellbores are easy to collapse, the drill is easy to be buried, and the annular tubes are difficult to be assembled during the drilling procedure, resulting in low extraction, rapid decay, and poor engineering results.

Indirect Vertical Fracturing Connectivity (IVFC) as applied to CBM stimulation was first proposed in 2003 by Olsen and Brenize [10]. This study presents several examples of the application of indirect fracturing. This is a technology that is not directly fracturing the target coal seam but fracturing the adjacent conventional rock strata, resulting in fractures effectively connecting the target layer by passing through the interface. The first well-documented case [11] of 
IVFC being applied in CBM was a lawsuit in New Mexico. Although this technique achieved success in practice [12], the fracturing process is still empirical and an in-depth investigation is needed to optimize the technology.

Many efforts have been made to deal with fracture complexity when hydraulic fractures encounter with unconformities in the rock medium such as joints, faults, cleats, natural fractures, and bedding planes [9, 13-17]. A key factor determining complex fracture patterns is the mechanical properties of natural fractures and interfaces. Anderson [18] (1981), Teufel and Clark [19] (1984), and Olsen and Bratton [11] (2007) pointed out that the shear stress of the interface between the interlayer plays an important role in that the fracture can extend through the barrier or along with the interface. Simonson et al. [20] (1978) investigated that a hydraulic fracture in a higher Young's modulus formation can penetrate across the interface to a lower modulus layer and can halt a fracture from a lower modulus layer. Defuel and Clark [21] (1981), Abass et al. [22] (1990), Wu et al. [23] (2017), and Yang et al. [24] (2020) drew out the similar conclusion.

This study carries out systematic experimental studies on indirect hydraulic fracturing using coal-rock combination samples. In the experiment, both the cuboid combination samples and plate samples are used. The formed types of specimens are helpful for understanding the indirect fracturing in 3D cases, and the latter is beneficial for visualizing the complicated fracture pattern. The work can offer insights into the fracture behavior in the indirect fracturing process and help optimize the technology.

\section{Experimental Apparatus and Methodology}

2.1. Experimental Samples. The tested raw samples were taken from the coal and its roof sandy mudstone in the northeastern part of the Qinshui Basin of Shanxi in China. For the ease of observation of hydraulic fractures, the standard two-dimensional coal-rock combination plate $300 \mathrm{~mm} \times 300 \mathrm{~mm} \times 50 \mathrm{~mm}$ samples were cast with concrete. The coal sample was processed to a $200 \mathrm{~mm} \times 100 \mathrm{~mm} \times 50 \mathrm{~mm}$ plate specimen with a wire cutting device, and the stratification of coal was marked before casting the specimen. The combination plates were prepared with a mixture of cement No. 425 and fine sand with a constant mass ratio being $1: 1$, and the average tensile stress of the concrete is about $2.95 \mathrm{MPa}$. A borehole with a diameter of $10 \mathrm{~mm}$ was drilled in a depth of $25 \mathrm{~mm}$ in the sample center. In order to simulate the large-scale threedimensional coal and rock mass hydraulic fracturing, the standard $300 \mathrm{~mm} \times 300 \mathrm{~mm} \times 300 \mathrm{~mm}$ cuboid samples were cast with concrete. The blocks were prepared by mixing cements of No. 425 and fine sand with a constant mass ratio of $1: 1.5$, and the average tensile stress of the concrete is about $2.04 \mathrm{MPa}$. A detailed schematic plot of standard samples with dimensions is shown in Figure 1.

To understand fracturing behaviors, one needs to know the mechanical properties of the sandy mudstone and coal mass, including fracture toughness $\mathrm{K}_{\mathrm{IC}}$, elastic modulus, Poisson's ratio, and tensile strength. The parameters were tested in different loading orientations with the bedding plane (Table 1).

Because in the specimens with large size, the main hydrofracture does not always completely pass through the entire specimen and number of secondary cracks may also be generated after hydraulic fracturing, the 3D hydrofracture propagation morphology in the large-scale cubic rock samples is difficult to be directly observed, even though the acoustic emission testing technology is used or the sample is opened along the main fracture. In order to investigate the hydrofracture characteristics and morphology in the coal-rock combination, two-dimensional coal-rock combination plate hydraulic fracturing tests were performed.

2.2. Experimental Apparatus. The experimental apparatus used to perform hydraulic fracturing simulation is a true triaxial simulation system with the model of TCHFSM-I, as shown in Figures 2 and 3. The system includes a triaxial servo control system, a hydraulic fracturing fluid injection system, a data acquisition system, and some auxiliary devices. The maximum load of the device is $300 t$, and the fluid injection system is equipped with a constant current/constant pressure pump. In the process of the hydraulic fracturing experiment, the constant current function was adopted.

In Table 2, before the $300 \mathrm{~mm} \times 300 \mathrm{~mm} \times 50 \mathrm{~mm}$ coalrock mass specimen is cast, the coal specimen is processed into a regular rectangular specimen. The interface between coal and concrete is naturally bonded by the cohesive force of concrete itself. The coal-rock interface is a flat surface to ensure uniform stress distribution on it. In the loading process, the maximum principal stress is only $4 \mathrm{MPa}$, which will not lead to the failure of coal and rock in the specimen after testing.

2.3. Experimental Methodology and Procedure. In order to investigate the characteristics and patterns of hydrofractures when they cross the coal-rock interfaces, two-dimensional coal-rock combination plate hydraulic fracturing and largescale cubic coal and rock mass fracturing were conducted in this experiment. Hydraulic fracturing simulation experimental program on combination samples is designed as shown in Table 1.

To visually observe the effects of the hydrofracture on the coal-rock combination and avoid the hydrofracture damage due to the vibration caused by opening the specimen along the main fracture, the two-dimensional coal-rock combination plate hydraulic fracturing experiment was designed in this study. After the bedding orientation of the coal plate was marked, the plate samples were cast with concrete. A borehole with a $10 \mathrm{~mm}$ diameter was drilled from the center of the surface to a depth of $25 \mathrm{~mm}$. A steel sleeve with a length of $20 \mathrm{~mm}$ was then fixed to the hole to simulate the wellbore, leaving a $5 \mathrm{~mm}$ free open-hole section, which was sealed by a specific chemical glue. In the process of coal-rock combination hydraulic fracturing, the fracture was propagated from rock to coal. In order to ensure the continuous 

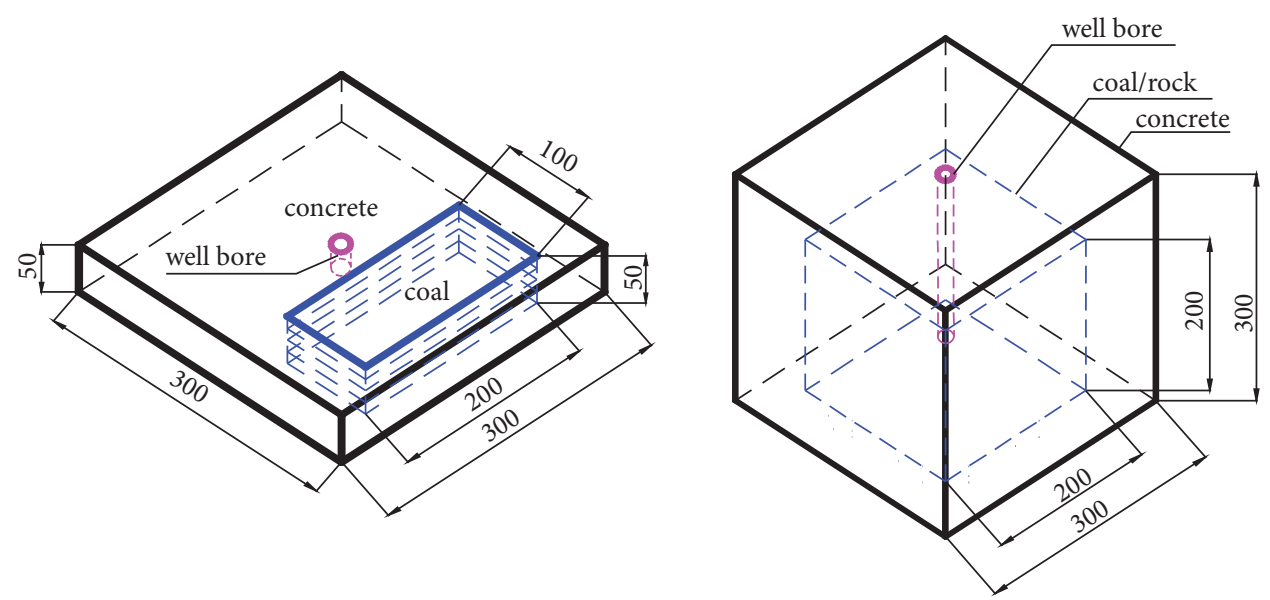

FIGURE 1: Schematic plot of standard samples with dimensions.

TABLE 1: The mechanical properties of the coal-rock and concrete.

\begin{tabular}{|c|c|c|c|c|c|}
\hline $\begin{array}{l}\text { Combination } \\
\text { sample }\end{array}$ & Remarks & $\begin{array}{l}\text { Average tensile stress/ } \\
\qquad \mathrm{MPa}\end{array}$ & $\begin{array}{l}\text { Average elastic modulus/ } \\
\mathrm{GPa}\end{array}$ & $\begin{array}{l}\text { Average Poisson's } \\
\text { ratio } \\
\end{array}$ & $\begin{array}{c}\text { Average } K_{\mathrm{IC}} / \\
\mathrm{MPa} \mathrm{m}^{1 / 2}\end{array}$ \\
\hline \multirow{2}{*}{ 15\# coal } & & 1.50 & 0.66 & 0.28 & 0.16 \\
\hline & $(-()+1)$ & 1.84 & 3.48 & 0.23 & 0.23 \\
\hline \multirow{2}{*}{ Sandy mudstone } & 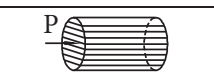 & 3.17 & 6.58 & 0.19 & 1.12 \\
\hline & $(-1)$ & 11.86 & 10.52 & 0.14 & 1.84 \\
\hline \multirow[b]{2}{*}{ Concrete } & Mass ratio $1: 1$ & 2.95 & 3.36 & 0.21 & 0.27 \\
\hline & $\begin{array}{c}\text { Mass ratio } 1: \\
1.5\end{array}$ & 2.04 & 2.81 & 0.24 & 0.19 \\
\hline
\end{tabular}

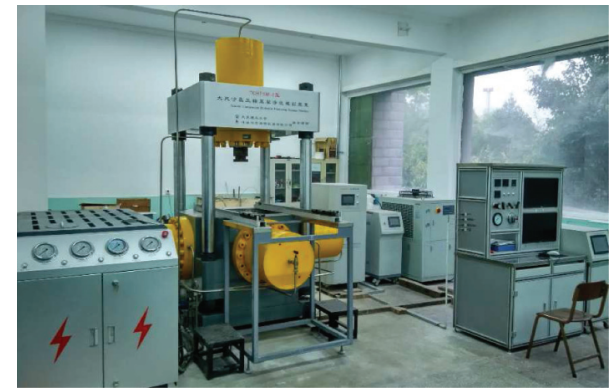

FIgURE 2: True triaxial fracture simulation machine.

propagation of the hydraulic fracture inside the specimen after initiation, rubber pads were employed to seal the upper and lower surfaces of the coal-rock composite plate specimen during the experiment. The fracturing fluid is clean water with a viscosity of about $0.001 \mathrm{~Pa}$.s under the temperature $20^{\circ} \mathrm{C}$. The injection rate of the combination plate is $50 \mathrm{ml} / \mathrm{min}$.

In order to further investigate the characteristics of hydraulic fracturing, three-dimensional large-size coal-rock specimens were used for the fracturing test. The coal-rock samples were cast in the middle of the cubic sample with concrete after the bedding orientation of the coal-rock mass was marked. A central $\varnothing 18 \mathrm{~mm}$ hole was drilled in a depth of
$230 \mathrm{~mm}$. A fracture steel tube with a length of $180 \mathrm{~mm}$ was then fixed to the hole to simulate the wellbore, leaving a $50 \mathrm{~mm}$ free open-hole section. The hole-sealed section was sealed by a specific chemical glue. The injection rate of the cubic sample is $100 \mathrm{ml} / \mathrm{min}$.

\section{Analysis of Fracturing Energy}

The opening of the fracture tip causes the strain energy to be released, resulting in a driving force that leads to the growth of the fracture. The energy release rate (fracture driving force) can be obtained by comparing the total strain energy before and after the fracture propagation.

According to the fracture energy model of Griffith [25] (1920), we assume that the coal or rock material is an infinite plate with a central crack subjected to uniaxial uniform tensile stress. In addition, it is postulated that the strain field of the crack tip without thermal energy changed during the deformation process. At last, we suppose that coal and rock are linear elastic materials. When the unit thickness of the plate is extended for a short length under critical stress (crack length from $2 a$ to $2 a+2 d a$ ), the released strain energy in the periphery of the fracture tip is equal to the surface energy, which is required to form the fracture area: 


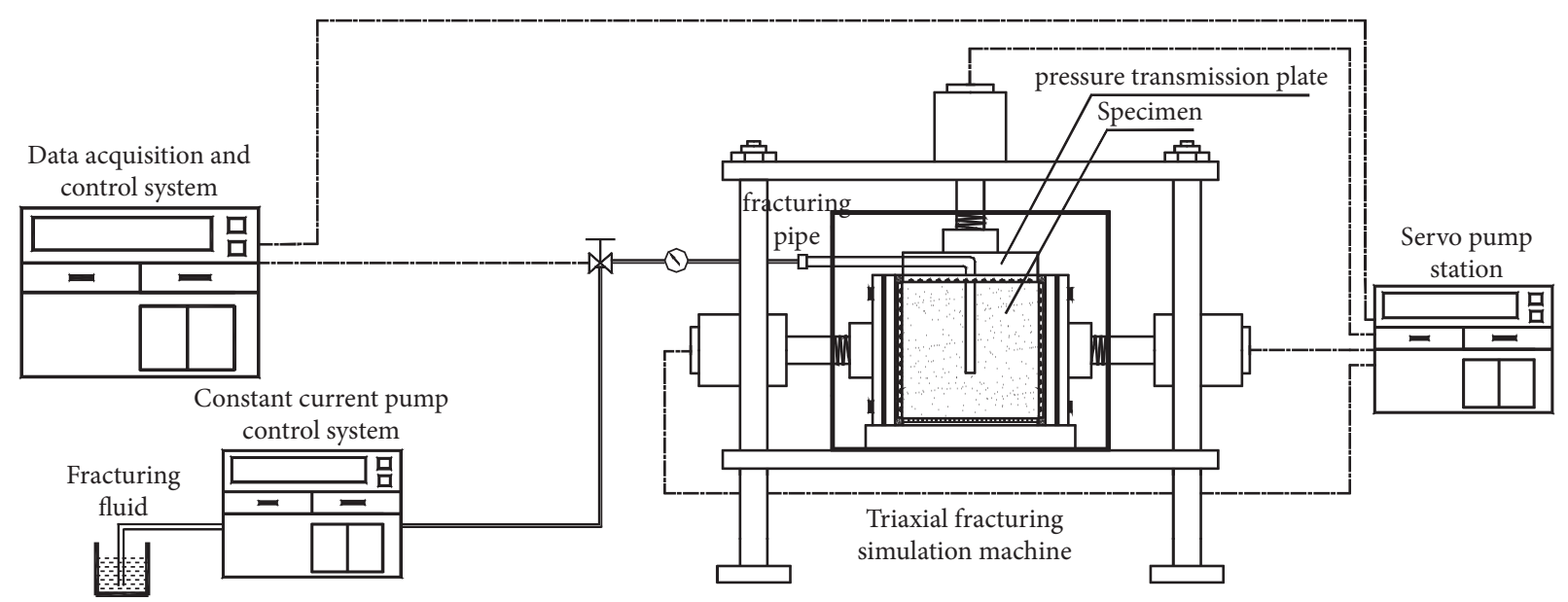

FIgURE 3: Schematic diagram of the hydraulic fracturing test system.

TABLE 2: Hydraulic fracturing simulation experimental program on combination samples.

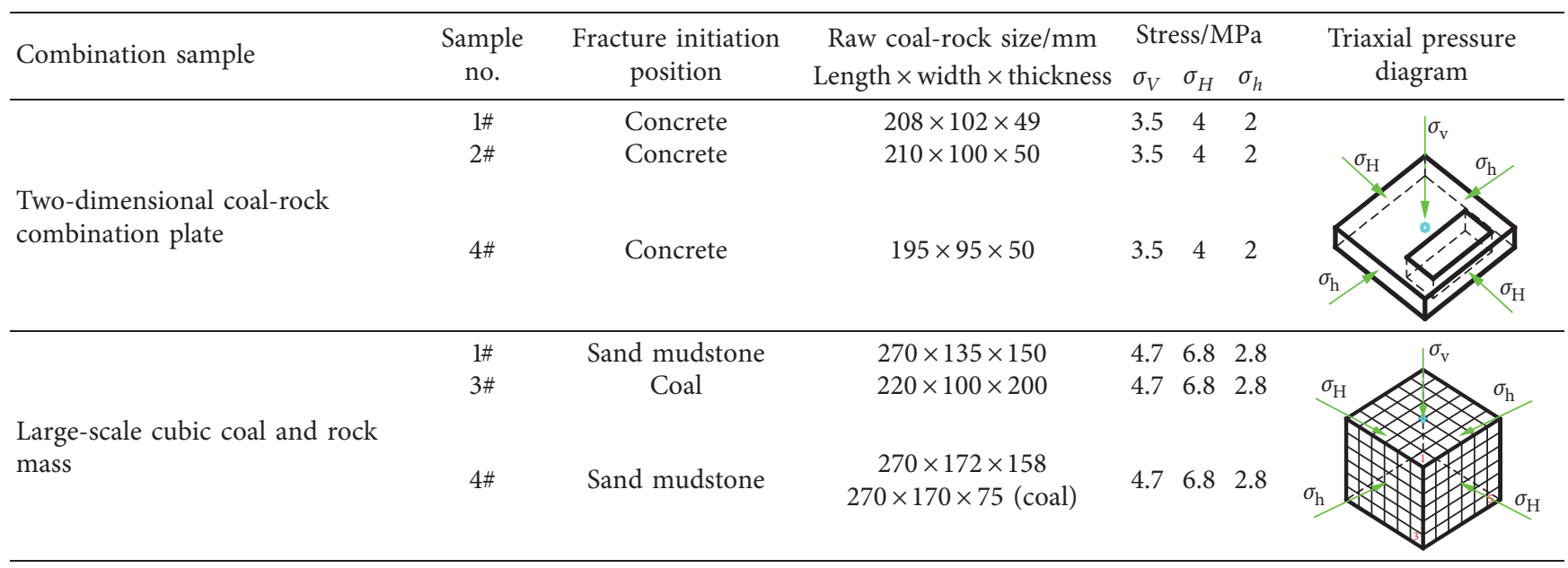

$$
\sigma_{f}=\sqrt{\frac{2 E \Gamma}{\pi a}},
$$

where $\Gamma$ is the unit area surface energy, $\mathrm{J} / \mathrm{m}^{2} ; E$ is the elasticity modulus, $\mathrm{GPa}$; $\mathrm{a}$ is the fracture length, $\mathrm{mm} ; \sigma_{\mathrm{f}}$ is the fracture driving force, $\mathrm{MPa}$.

In the calculation, the fracture driving force $\sigma_{\mathrm{f}}$ is approximately replaced by the tensile strength $\sigma_{\mathrm{t}}$ of coal and rock samples. According to the tensile strength in the direction perpendicular to the bedding plane of coal and sandy mudstone (sm) by $\mathrm{Wu}$ [23] et al. (2017),

$$
\begin{aligned}
\sigma_{\mathrm{tsm}} & =9.83 \sim 12.66 \mathrm{MPa}, \\
E_{\mathrm{sm}} & =9.81 \sim 11.23 \mathrm{GPa}, \\
\sigma_{\text {t coal }} & =1.24 \sim 1.97 \mathrm{MPa}, \\
E_{\text {coal }} & =2.75 \sim 4.21 \mathrm{GPa},
\end{aligned}
$$

and substituting these values into formula (1).

$$
\Gamma_{\text {sm }}=10.69 \sim 25.53 \text { Coal. }
$$

Under the ideal linear elastic conditions, the energy required for crack propagation is the same as the energy released by crack opening. It can be seen from results (3) that under the ideal linear elastic condition, when the crack initiating in the sandy mudstone and fracturing through the interface to the soft coal body, the strain energy released by the crack tip in the sandy mudstone can be used to generate 10.69 25.53 times equivalent length or a number of branches in the coal body, which is conducive to form a multicrack structure.

\section{Experimental Results and Discussion}

4.1. Characteristics of Hydrofracture Propagation in CoalRock Combination Plate. The size of the length, width, and thickness of the two-dimensional coal-rock combination plate sample is $300 \mathrm{~mm} \times 300 \mathrm{~mm} \times 50 \mathrm{~mm}$. The mass ratio of cement No. 425 and fine sand is $1: 1$. The schematic plot of the triaxial loading orientation of the coal-rock combination plate and the hydrofracture morphology are shown in Figure 4 . The pressure-time curve in the process of fracturing is shown in Figure 5.

As shown in Figure 4(a), the maximum principal stress orientation of the $1 \#$ combination plate is parallel to the coal bedding plane, and the fracturing path is initiating fractures in the rock and allowing the induced fractures to connect 


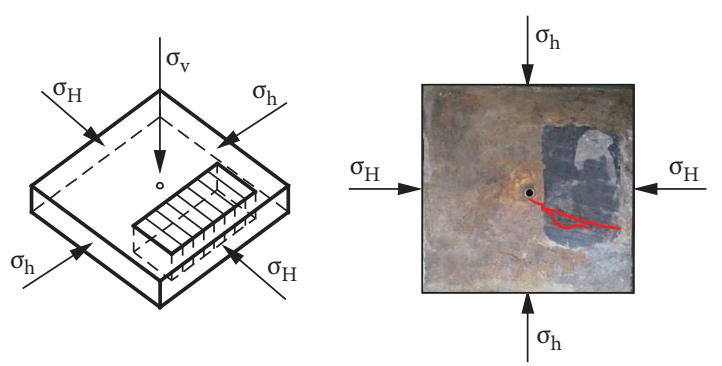

(a)

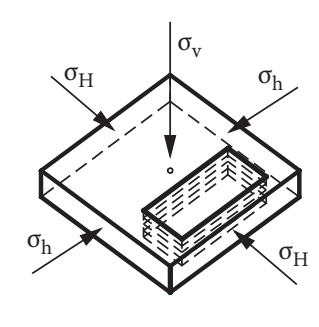

(b)

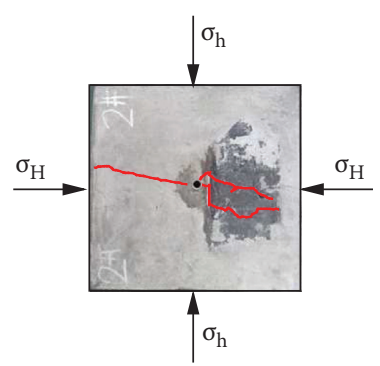

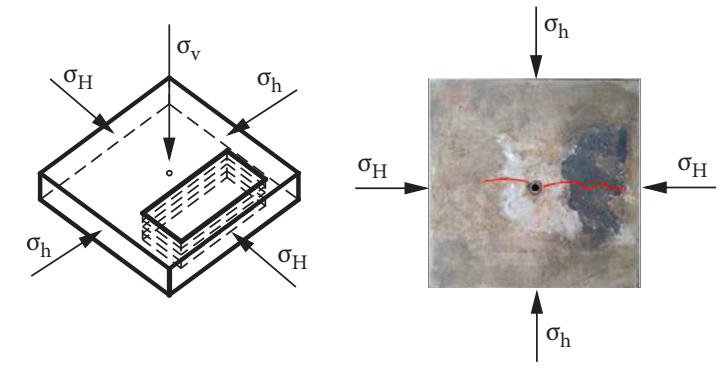

(c)

FIgURE 4: The hydraulic fracture morphology of the combination plate. The hydrofracture morphology of (a) 1\# combination plate, (b) 2\# combination plate, and (c) $4 \#$ combination plate.

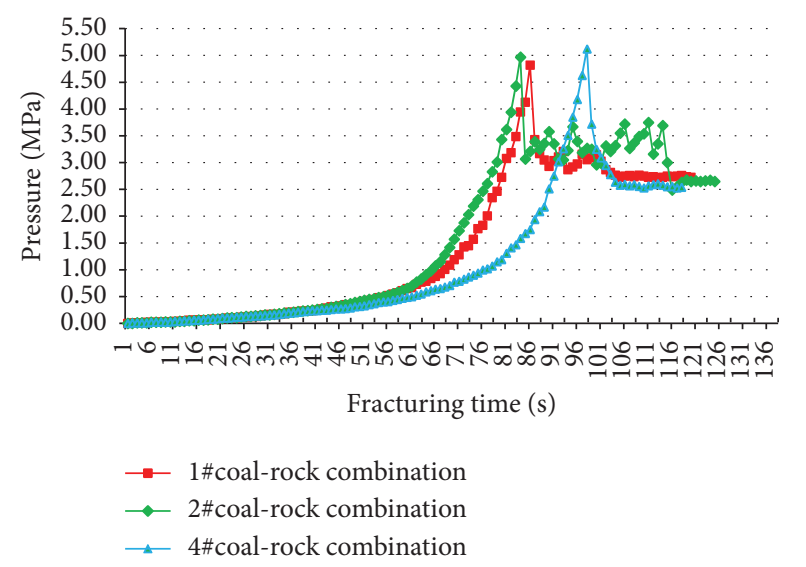

FIGURE 5: The pressure-time curve of platy coal-rock combination.

and grow into the coal mass. Taking a panoramic view of the fracture propagation morphology, a narrow crack initiates in the concrete and propagates into the coal mass, and the crack branches in the coal mass after crossing the interface.

The hydrofracture obviously presented a "deflection" fracture when the fracture extension encounters the interface. There is a slight offset or shear slippage in the interface, whose propagation path is shown in Figure 4(a). As shown in Figure 5, the fracturing pressure reached a peak value of $4.82 \mathrm{MPa}$ at $86 \mathrm{~s}$, and then, the pressure sharply dropped to $2.93 \mathrm{MPa}$. Combined with crack propagation morphology, the fracture initiated in the concrete.

(1) Hydraulic fracturing experiments with quasi twodimensional coal-rock combination plate specimens were conducted, and the fracture propagation characteristics through the coal-rock interface were studied.
(2) The hydraulic fractures and their propagation characteristics among the combined specimens of coal and sandy mudstone were investigated through the experiments of hydraulic fracturing in large size coal-rock cube specimens.

(3) With the energy theory of the Griffith, the released strain energy of the fracture per unit length in the sandy mudstones is compared with the coal in the direction vertical to the bedding plane, and the results demonstrated that the energy produced in the hard rock by hydraulic fracturing is several times as that assumed in the coal to form complex fractures.

(4) A new method to produce complex fracture system in the coal strata is proposed through hydraulic fracturing in the overlying rock layer based on this study.

In the subsequent process of fracture propagation, the pressure fluctuation presents several lower peaks of $3.2 \mathrm{MPa}$, 3.16 MPa, and 3.15 MPa. Combined with the tensile strength of the coal and the minimum principal stress, these peak stresses are the fracturing pressures of the fracture propagation in the coal mass.

As shown in Figure 4(b), the maximum principal stress orientation of the $2 \#$ combination plate is perpendicular to the coal bedding plane, and in such case, the fracture initiated in the concrete and can grow into the coal mass. It can be seen from the overall fracture propagation morphology that the penetration fractures become complicated when hydraulic fractures intersect the interface. There are two irregular fractures on the coal area along the direction perpendicular to the coal bedding plane and an obvious shear slippage at the interface. In the process of hydraulic fracturing, the critical fracturing hydropressure in the 
concrete area reached the peak of $4.97 \mathrm{MPa}$ at $84 \mathrm{~s}$ and then sharply dropped to $3.07 \mathrm{MPa}$ (seen in Figure 5). In the subsequent process of fracture propagation, the pressure presents frequent fluctuations, and the fluctuation range of the pressure peak is 3.6 3.8 MPa. Combined with the tensile strength of the coal in the direction perpendicular to the bedding plane and the minimum principal stress, it is predicted that these peak stresses are the fracturing pressure of the fracture propagation in the coal mass.

As shown in Figure 4(c), the maximum principal stress orientation is perpendicular to the coal bedding plane, and the fracturing path is initiating fractures in the concrete and allowing the induced fractures to grow into the coal mass. Taking a panoramic view of the fracture propagation morphology, we can find that an irregular fracture directly penetrates the interface and grows into the coal on the right side of the fracturing tube. In the progress of the hydraulic fracturing, the critical fracturing pressure reached a peak of $5.12 \mathrm{MPa}$ at $98 \mathrm{~s}$, and then, the pressure sharply dropped to about 2.7 MPa (seen in Figure 5). In the subsequent process of the fracture propagation, the fluctuation of pressure trends to be flatter.

In conclusion, from the point of the hydrofracture morphology of the two-dimensional coal-rock plate combination, it is more convenient for the complex fracture system formation for the fractures initiating in the hard rock and allowing the induced fractures to connect and grow into the coal mass.

4.2. Characteristics of Indirect Hydraulic Fracturing in $3 D$ Large-Scale Coal-Rock Mass. To further investigate the 3D hydrofracture propagation characteristics, hydraulic fracturing tests were performed on 3D large-size combined specimens of coal and sandy mudstone.

To obtain the fracture spatial morphology evolution characteristics in the cubic sample, a NM-4A nonmetal ultrasonic detector was used to detect the sound wave time and wave speed of relevant parameters before and after hydraulic fracturing. Before testing, the specimens were placed at room temperature for 7 days to insure the fractured specimens were in a dry status. In the process of ultrasonic testing, it is assumed that the linear distance $L$ between the transducers is the propagation distance, and the acoustic wave directly propagates across the air medium when it encounters the fracture. The spatial morphology of the crack in the specimen is plotted by testing the variation of the sound velocity of the three-dimensional corresponding point of the specimen.

Note that this test method is not as rigorous or as accurate as methods, but this test methodology will, however, afford rewarding relative comparisons. The sketch map of raw coal-rock mass and the triaxial stress orientation is shown in Figure 6. The hydrofracture morphology of the sample is shown in Figure 7.

Initiating fractures in the hard sandy mudstone allows these induced fractures to grow into the concrete. As shown in Figure 6(a), the maximum principal stress orientation of the $1 \#$ sandy mudstone-concrete sample is perpendicular to the bedding plane. Taking a panoramic view of the 3D fracture propagation morphology, it can be seen that the main fractures extend along with the maximum principal stress in the direction perpendicular to the bedding plane (Figure 7(a)), and the fracture pattern exhibits complex morphology. Particularly, the fracture pattern tends to be complex in the interface in the lower part of the specimen, presenting characteristics of diversion and offset. This test shows that initiating fractures in the hard sandy mudstone can allow these induced fractures to grow into the concrete and be conducive to the formation of a multifracture system.

As shown in Figure 8, the critical fracturing hydropressure in the sandy mudstone in the direction perpendicular to the bedding plane reached the peak of $12.01 \mathrm{MPa}$ at $47 \mathrm{~s}$, and then, the pressure sharply dropped to about 4.05 MPa. Later, another peak pressure was monitored during the subsequent fracture propagation to $5.07 \mathrm{MPa}$ at 51 s. Subsequently, water flow was observed below the fracturing chamber, and the fracturing pressure was approximately stabilized at $1.83 \mathrm{MPa}$.

Fracture initiates in the coal mass and propagates to the edge of concrete. As shown in Figure 6(b), the maximum principal stress orientation of the $3 \#$ coal-concrete combination sample is perpendicular to the bedding plane. Taking a panoramic view of the $3 \mathrm{D}$ fracture propagation morphology, it can be seen that the main fracture extends along with the maximum principal stress in the direction perpendicular to the bedding plane (Figure $7(b)$ ), and the fracture pattern exhibits a single shape. The test shows that initiating fractures in the soft coal mass is not easy to form a multifracture system.

In the $3 \#$ coal-concrete combination specimen, due to the tensile strength of the coal mass in the direction perpendicular to the bedding plane is close to the concrete, the fracturing pressure of the coal mass in the direction perpendicular to the bedding plane is near to the concrete. As shown in Figure 8, the critical fracturing hydropressure in the coal mass in the direction perpendicular to the bedding plane reached the peak of $4.94 \mathrm{MPa}$ at $44 \mathrm{~s}$, and then, the pressure sharply dropped to about $2.58 \mathrm{MPa}$. Later, another peak pressure was monitored during the subsequent fracture propagation to $5.07 \mathrm{MPa}$ at $51 \mathrm{~s}$. Subsequently, water flow was observed below the fracturing chamber, and the fracturing pressure was approximately stabilized at $1.75 \mathrm{MPa}$.

In terms of the $4 \#$ coal specimen, the fracture initiates in the sandymudstone mass and propagates to the edge of the specimen. As shown in Figure 6(c), the maximum principal stress orientation is perpendicular to the bedding plane. In the case of the overall fracture propagation morphology as shown in Figure 7(c), the whole fracture pattern is extremely complex, and the main fractures extend along with the maximum principal stress in the direction perpendicular to the bedding plane. In the ultrasonic testing process, since the acoustic time variation of most points is out of range, the data cannot accurately reflect the internal fracture morphology, especially the secondary fracture morphology, which further illustrates the complexity of the internal fracture shape of the specimen. 

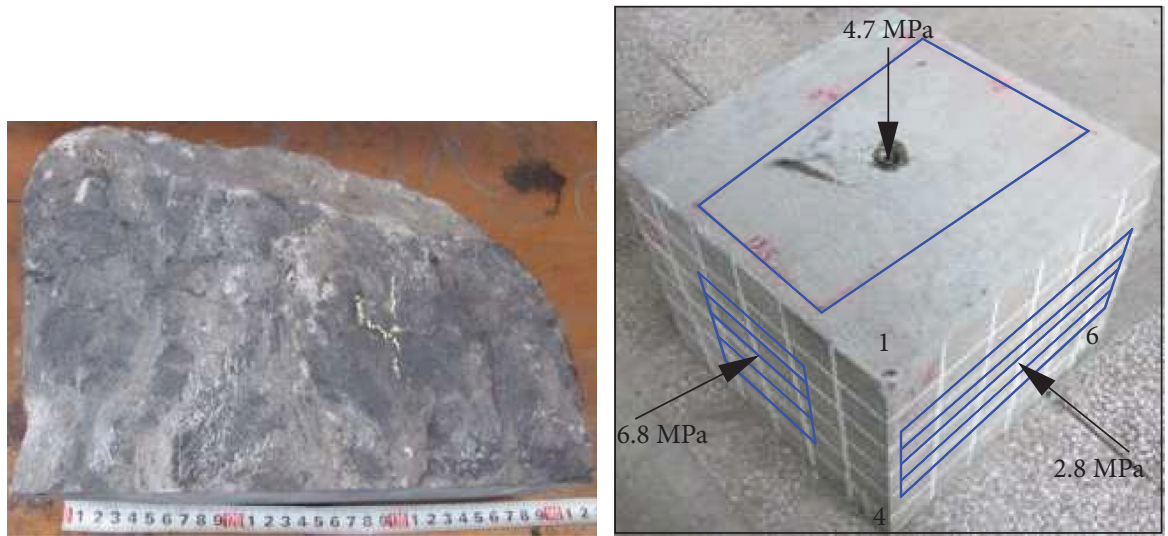

(a)

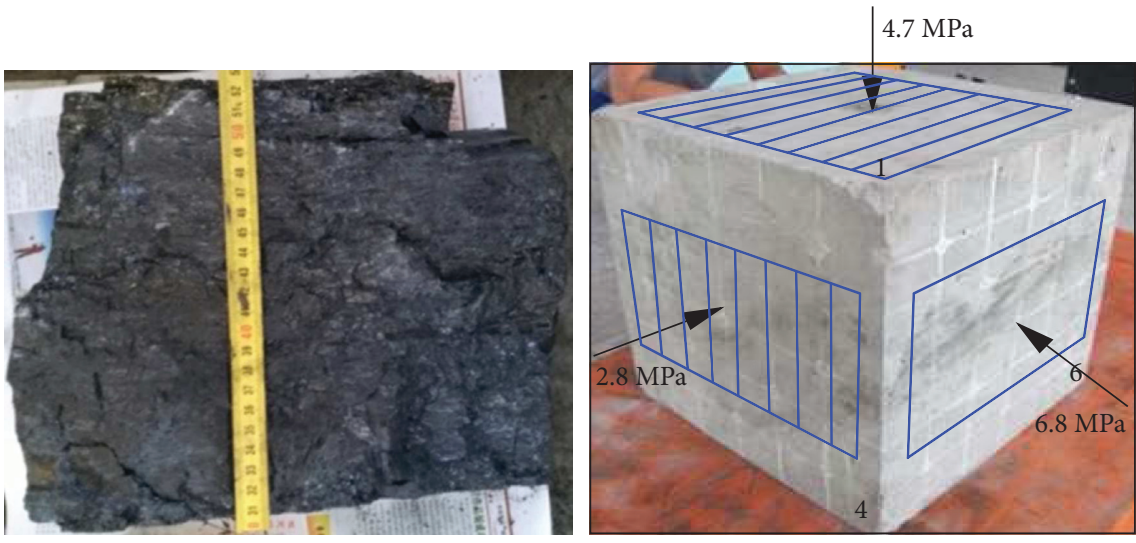

(b)
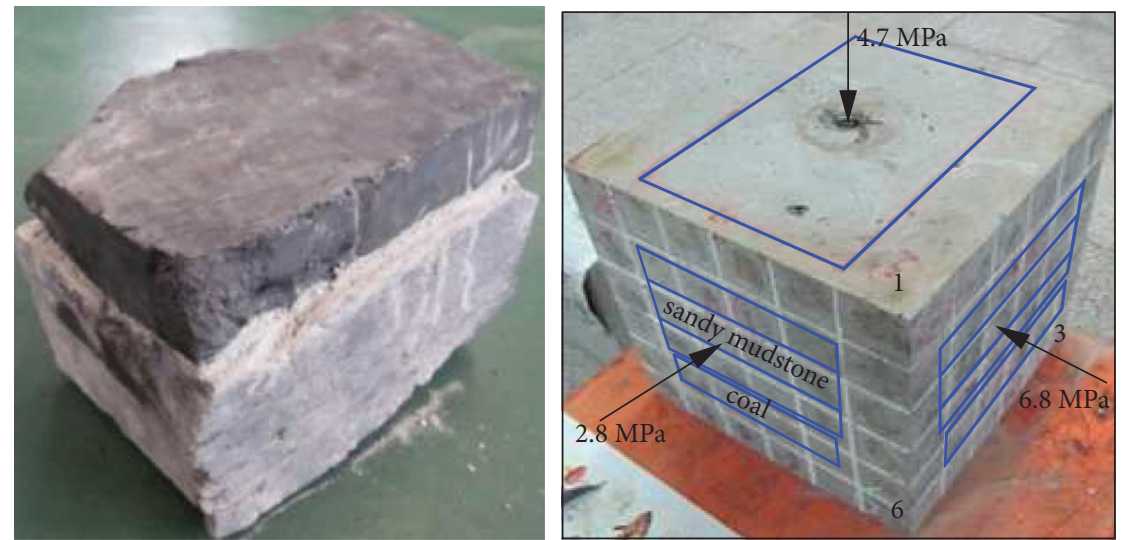

(c)

FIGURE 6: Diagram of coal-rock samples and their triaxial stress orientation. (a) 1\# sandy mudstone sample. (b) 3\# coal sample. (c) 4\# coalsandy mudstone combination sample.

As shown in Figure 8, the critical fracturing hydropressure in the coal mass in the direction perpendicular to the bedding plane reached the peak of $13.84 \mathrm{MPa} \mathrm{MPa}$ at $44 \mathrm{~s}$, and then, the pressure sharply dropped to about 2.92 MPa. Later, three peak pressure values were monitored during the subsequent fracture propagation, respectively, 5.25 MPa, 4.57 MPa, and 4.79 MPa. These three lower peak pressure values are considered as the initiation pressure values, which were monitored in the process of the fractures growing into the coal or concrete. Subsequently, water flow was observed below the fracturing chamber, and the fracturing pressure was approximately stabilized at $2.20 \mathrm{MPa}$.

\section{Engineering Practice}

Zhaozhuang Coal Mine in Qinshui Coalfield is located in the lower part of the Shanxi Formation as shown in Figure 9. It is No. 3 coal seam that has strong plasticity and well-developed fractures, but the fracture connectivity is poor, the filling and clogging are serious, and the degree of reduction in the 

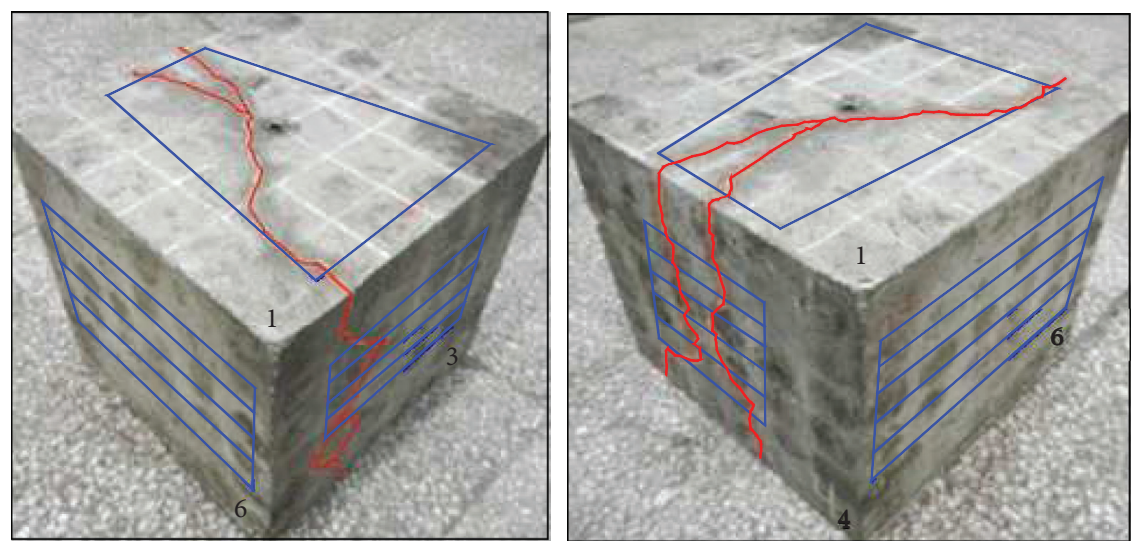

(a)
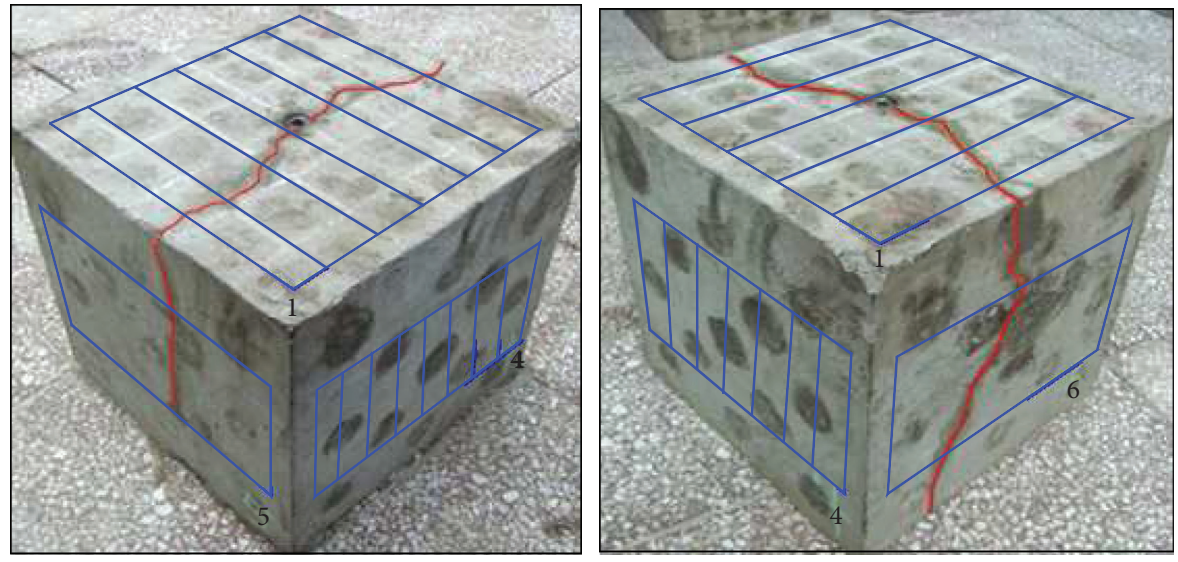

(b)
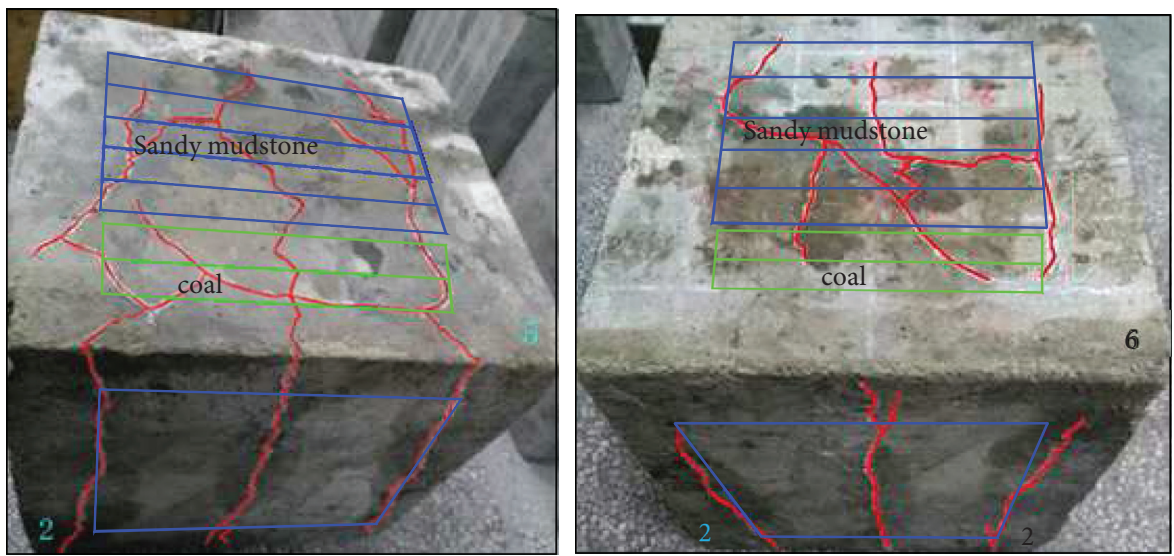

(c)

Figure 7: The hydrofracture morphology of the 3D coal-rock combination sample. The fracture morphology of (a) 1\# sandy mudstone sample, (b) 3\# coal sample, and (c) 4\# coal-rock combination sample.

drainage and pressure reduction in coal-bed methane wells is small, resulting in poor gas production. The daily production of 47 vertical wells is below $500 \mathrm{~m}^{3}$.

In 2017-2018, Lanyan Coalbed Methane Group Co., Ltd. and scientific research institutions jointly conducted a roof horizontal well indirect hydraulic fracturing engineering on the No. 3 coal roof in Zhaozhuang Coal Industry Co. Ltd. The horizontal well is about $800 \mathrm{~m}$ long, and it is arranged in the roof sandy mudstone layer $1.5 \sim 2 \mathrm{~m}$ away from the coal seam (seen in Figure 9). The implementation of roof horizontal well indirectly fracturing coal seams to increase CBM production has been successful, achieving a daily output of $7,000 \mathrm{~m}^{3}$.

\section{Discussion of Crack Propagation in Coal-Rock Interface}

In the progress of the two-dimensional coal-rock combination plate hydraulic fracturing experiment, it can be seen 


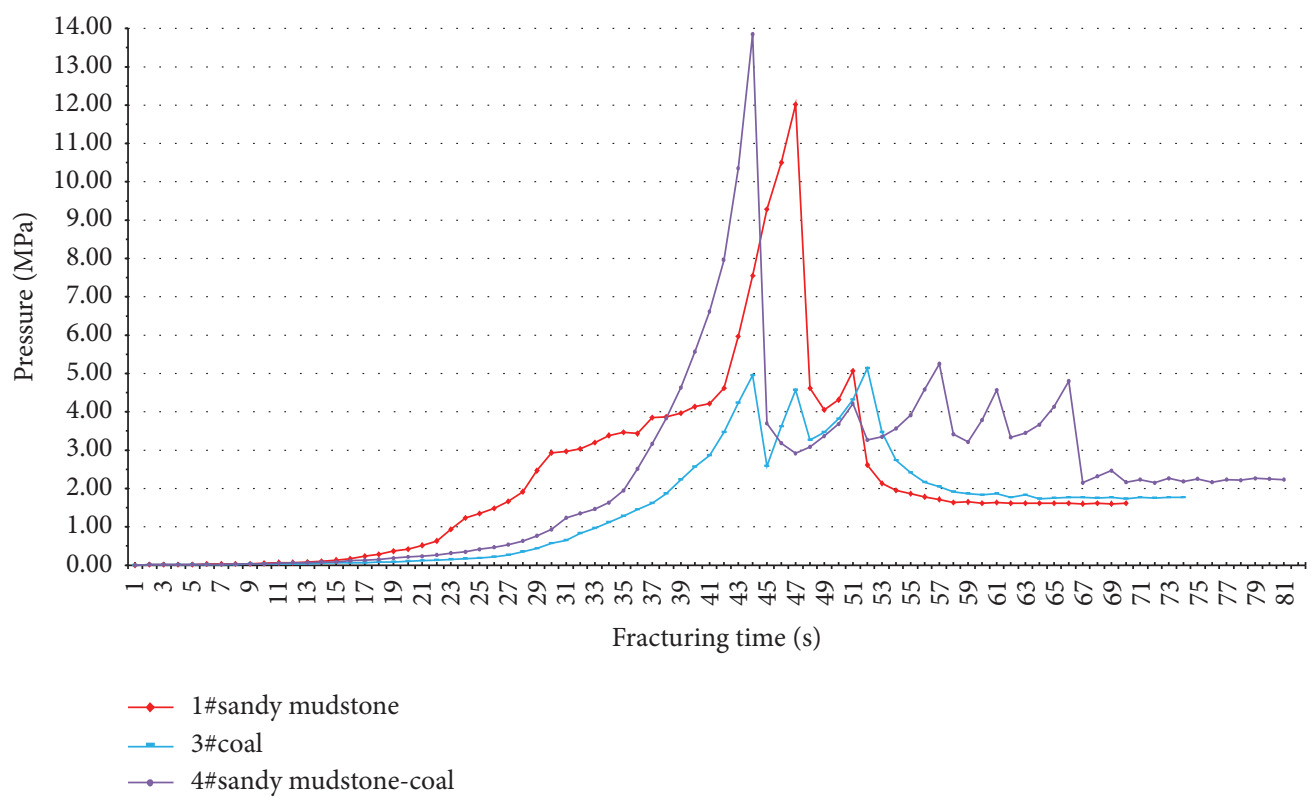

FIgURE 8: The press-time curve of coal-rock samples.

from the overall fracture propagation morphology (Figure 10) that most of the hydrofractures divert or offset when the fractures encounter the interface, which create complex fracture patterns. As Zeng and Wei [12] 2017 pointed out that the diversion or offset of hydrofractures is regarded as the key factor leading to the formation of the fracture system, Olsen $[10,11](2003,2007)$ also found the complex crack network when a fracture intersects with an interface by means of shear slippage.

The coal seam and its overlying layer are natural sediments, and their interface properties are discontinuous and unconformable, including many tiny defects and microcracks. Intuitively, coal and its overlying rock are two distinct materials, and the composite material should have four elastic constants, namely, two Young's modulus and two Poisson's ratios. In order to analyze the crack propagation problem at the interface, the interface mechanics model [26] was introduced to simplify the coal-rock interface and simplify it into an ideal interface in the sense of mechanics (seen in Figure 11), and there is no confining pressure or external force.

The ideal interface has no macroscopic defects on the bonding surface, and its interface continuity conditions satisfy the continuous conditions of surface force and displacement.

$$
\begin{aligned}
P_{i 1} & =P_{i 2}, \\
u_{i 1} & =u_{i 2}, \\
i & =1,2,3,
\end{aligned}
$$

where $P$ is surface force $(N)$; the normal vector relationship with stress and interface is given by Cauchy's formula $P_{i}=\sigma_{i j} n_{j} ; \mu_{i}$ represents the displacement in the $i$ direction, $\mathrm{mm}$; and subscripts 1 and 2 indicate the physical quantities corresponding to the coal and rock materials on both sides of the interface.
Due to the different physical properties of the coal-rock materials on both sides of the interface, the boundary conditions of the interface can be actually regarded as the constraint of the deformation of one side material on the other side. The existence of such constraints can cause stress concentration in the interface and its vicinity, especially in the sudden change in the interface geometry, and the stress concentration becomes more prominent. In the category of elastic mechanics, the point at which the stress tends to infinity is called a singular point. The stresses and displacements near the singular points on the interface can be expressed by

$$
\begin{aligned}
\sigma_{i j} & =\sum_{k=1}^{N} \frac{K_{k} f_{i j k}(\theta)}{r^{1-\lambda_{k}}}, \\
u_{i} & =\sum_{k=1}^{N} K_{K} r^{k} F_{i k}(\theta),
\end{aligned}
$$

where $r$ is the singular point distance, $\mathrm{mm} ; \lambda_{k}$ is the kth eigenvalue (determined by the geometry near the singular point and the properties of the material being bonded); 1 $\lambda_{k}$ is the stress singularity index (the larger the value is, the stronger the singularity of the point is); $K_{k}$ is the stress intensity coefficient (stress intensity factor) corresponding to eigenvalue $\lambda_{k}$ or stress singularity index $1-\lambda_{k}$; and $f, F$ is the angular function; $N$ is the number of singularity.

As shown in Figure 12, due to the strong anisotropy of the interface in the coal-rock composite materials, the positive and shear stresses must simultaneously exist near the tip of the crack regardless of the external load. Under the influence of the type II stress intensity factor, the crack will deviate from the interface.

In engineering, the maximum tangential stress $\left(\sigma_{\theta \max }\right)$ theory proposed by Shi [27] is often used to explain the crack deflection in homogeneous materials under the action of mixed 

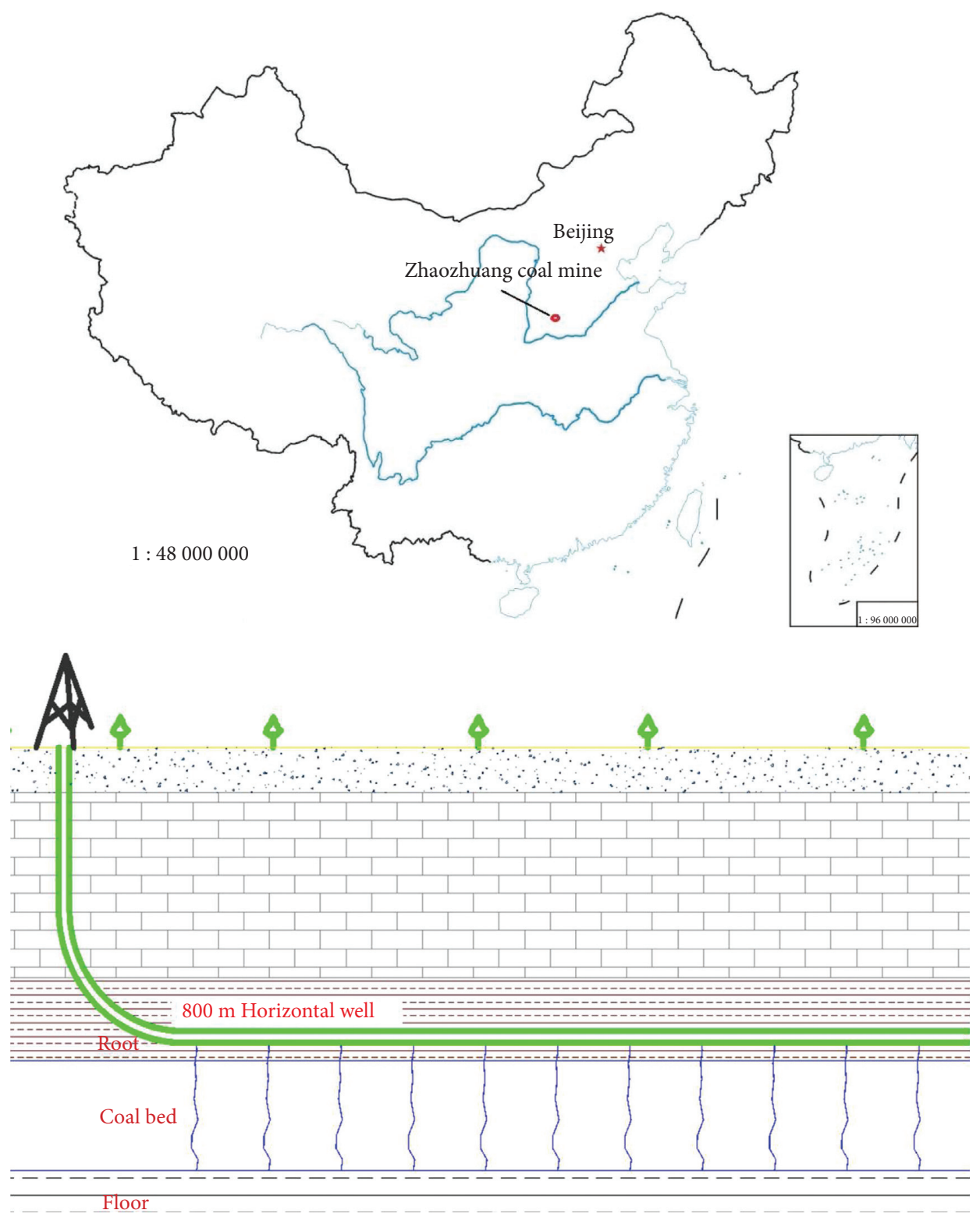

Figure 9: Regional map of Zhaozhuang Coal Industry Co., Ltd. and fracturing diagram.

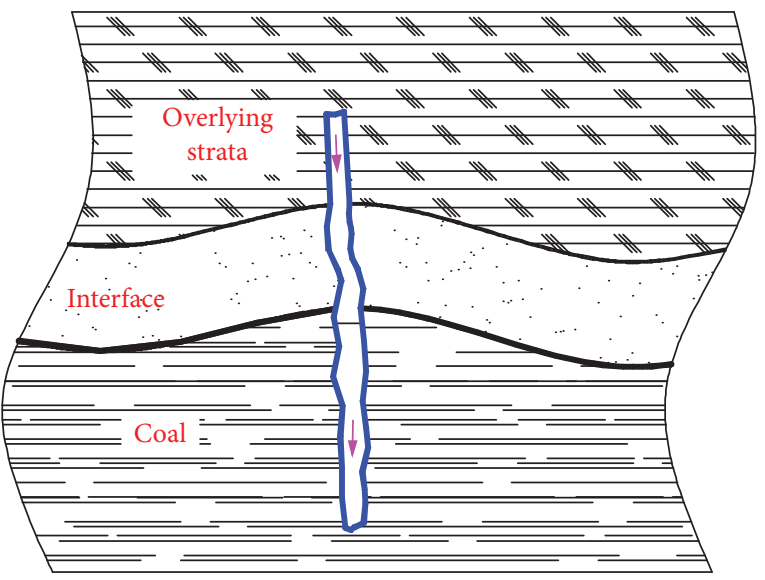

(a)

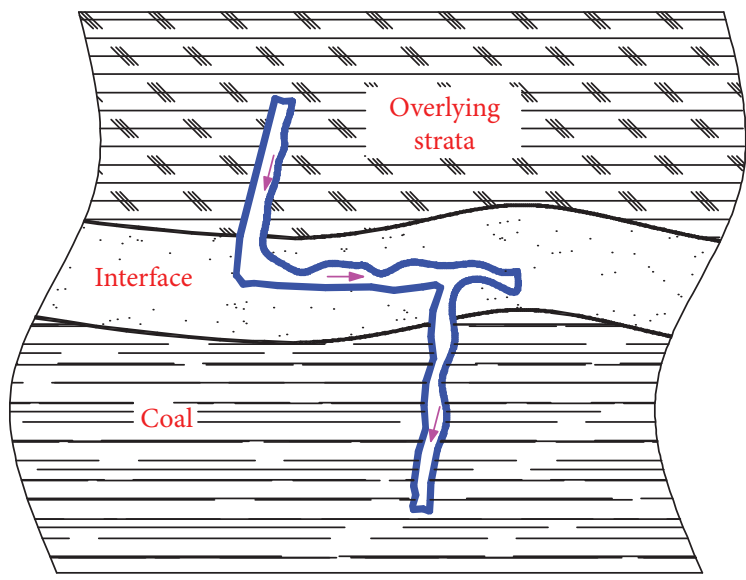

(b)

Figure 10: Continued. 


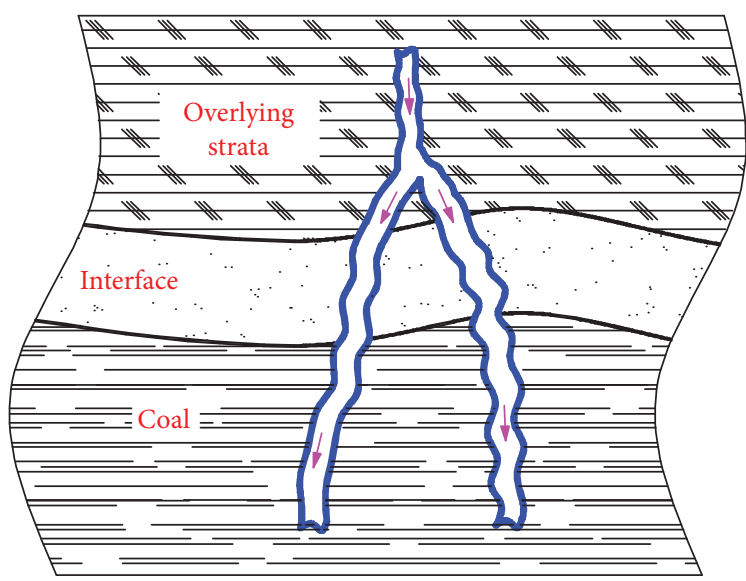

(c)

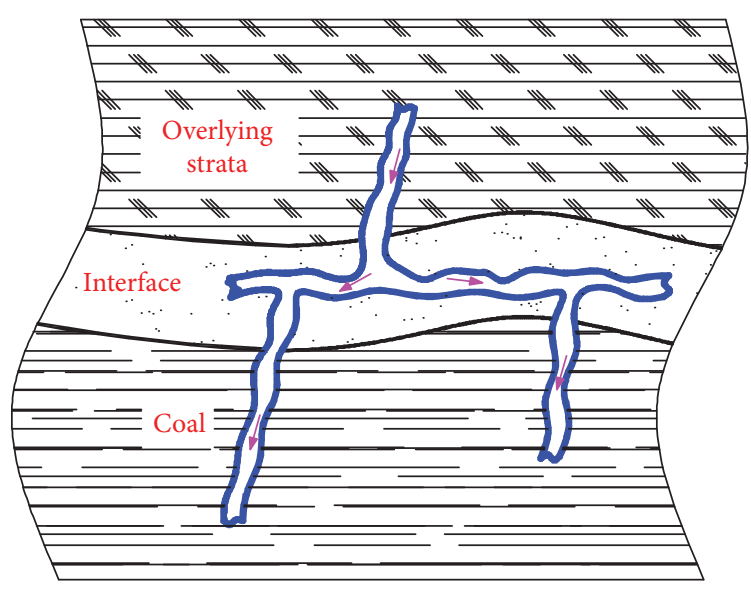

(d)

Figure 10: The complicated hydrofracture patterns of the indirect fracturing from the overlying strata. (a) Penetration type. (b) Deflection type. (c) Bifurcate compound type.

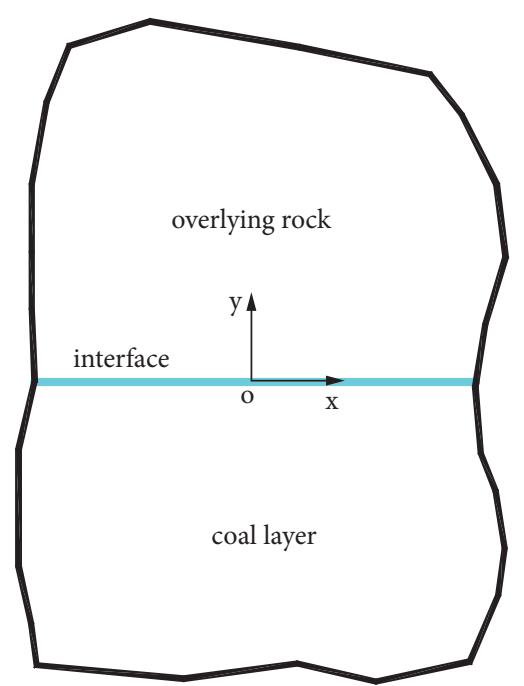

FIGURE 11: Ideal interface mechanic model.

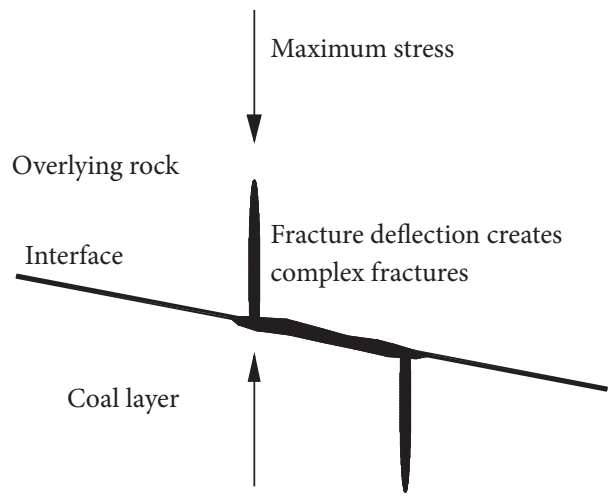

FIgURE 12: Complex fracturing. 


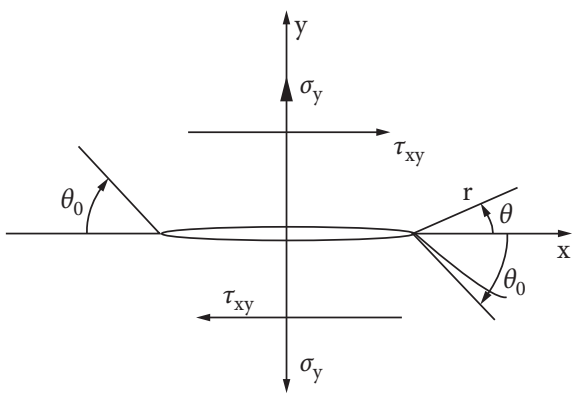

FIgURE 13: Zigzag failure of cracks in homogeneous materials under the mixed mode.

mode (I, II). The theory states that the crack will deflect to the direction of the largest $\sigma_{\theta \max }$ fixed in the polar coordinate system of the crack tip, and the crack initiation occurs when the equivalent stress intensity factor in this direction reaches the fracture toughness of the material, as shown in Figure 13.

The tangential stress field distribution near the crack tip in a homogeneous material is as follows:

$$
\sigma_{\theta}=\frac{K_{\mathrm{I}}}{\sqrt{2 \pi r}}\left[\frac{3}{4} \cos \frac{\theta}{2}+\frac{1}{4} \cos \frac{3 \theta}{2}\right]+\frac{K_{\mathrm{II}}}{\sqrt{2 \pi r}}\left[-\frac{3}{4} \sin \frac{\theta}{2}-\frac{3}{4} \sin \frac{3 \theta}{2}\right] .
$$

The direction of crack initiation is determined as follows:

$$
\begin{gathered}
\frac{\partial \sigma_{\theta}}{\partial \theta}=0 \\
\frac{\partial^{2} \sigma_{\theta}}{\partial \theta^{2}}<0
\end{gathered}
$$

where $\sigma_{\theta}$ is the shear stress at any point near the crack tip; $K_{\mathrm{I}}$, $K_{\mathrm{II}}$ is the stress intensity factors in homogeneous materials; $r$ is the distance from any point near the crack tip; and $\theta$ is the deflection angle of the crack initiation.

The stress field distribution at the crack tip of the anisotropic interface of the bimaterial is as follows:

$$
\begin{aligned}
\sigma_{\theta j}+i \tau_{r \theta j}= & \frac{\sqrt{K_{1}^{2}+K_{2}^{2}}}{2 \sqrt{2 \pi r} \cosh (\varepsilon \pi)}\left(\frac{r}{h a}\right)^{i \varepsilon}\left[W_{j} e^{i((\theta / 2)+\gamma)}+\frac{1}{W_{j}} e^{i((3 \theta / 2)+\gamma)}\right] \\
& +\frac{\sqrt{K_{1}^{2}+K_{2}^{2}}}{2 \sqrt{2 \pi r} \cosh (\varepsilon \pi)}\left(\frac{r}{h a}\right)^{-i \varepsilon} W_{j}\left[e^{-i((\theta / 2)+\gamma)}-(\cos \theta+2 \varepsilon \sin \theta) e^{i((\theta / 2)-\gamma)}\right], \\
W_{1}= & e^{-\varepsilon(\pi-\theta)}, \\
W_{2}= & e^{\varepsilon(\pi-\theta)}, \\
\gamma= & \arctan \left(K_{2} / K_{1}\right),
\end{aligned}
$$

where $\sigma_{\theta j}$ is the normal stress at the crack tip $(N)$; $\tau_{r \theta j}$ is the shear stress at the crack tip $(N) ; a$ is the half length of the crack $(\mathrm{mm}) ; h$ is the coefficient of taking a crack feature length; $\varepsilon$ is the oscillating factor of crack at the bimaterial interface; $W_{j}$ is the eigenvectors in Hamiltonian matrices; and $K_{2} / K_{1}$ is the stress intensity coefficient in the interface singular stress field (both related to normal stress and shear stress, which is different from $K_{\mathrm{I}}, K_{\mathrm{II}}$ in fracture mechanics).

When the crack has a tendency to deflect toward the lower strength coal strata side, under the condition of large $K_{2} / K_{1}$ (that is, the angle of steering expansion is larger), the deflection criterion will be reached first, and the crack will deflect and grow into the coal strata. However, under the condition of small $K_{2} / K_{1}$ (that is, the angle of steering expansion is smaller), the interface deflection criterion will be reached first, and the crack will propagate along with the interface. When it comes to the crack that has a tendency to deflect toward the hard overlying rock side, the crack will expand along with the interface because the interface deflection criterion will be reached first regardless of the $K_{2} / K_{1}$.

\section{Conclusions}

In this study, the hydrofracture properties and hydraulic fracturing propagation characteristics of the two-dimensional plate of coal-rock combination and large-size cuboid coal-rock specimen were investigated. The released strain energy of fracture initiation was analyzed by the fracture energy model of Griffith. The following conclusions can be drawn: 
(1) In the case that the fracture propagates from the sandy mudstone to the coal bed, the released strain energy (per unit length) in the sandy mudstone is 10.69 25.53 times greater than that in the coal mass.

(2) Depending on the mechanical properties of coalrock interfaces, the diversion or offset of the fractures takes place at the interface, leading the fracture patterns to be complex, which will improve the fracture system.

(3) When the fracture has a tendency to deflect toward the lower strength coal strata, under the condition of large $K_{2} / K_{1}$, the deflection criterion will be met first and the fracture will deflect and grow into the coal strata.

(4) The indirect fracturing engineering practice of horizontal well in Zhaozhuang Coal Industry Co., Ltd. proves that cracks can propagate through the coal-rock interface and that indirect fracturing is feasible.

This study confirms the feasibility of indirect fracturing, which initiates fractures in hard sandy mudstone roofs and drives them to soft coal seams through fluid pressure. The hydrofracture system can be improved by fracturing from the overlying hard strata to the soft coal seam.

The length and the width of the coal or rock mass refer to the respective distance along the bedding plane, and the thickness refers to the distance perpendicular to the bedding plane. The fracturing fluid is clean water with a viscosity of about $0.001 \mathrm{~Pa} \cdot \mathrm{s}$ under the temperature $20^{\circ} \mathrm{C}$. The injection rate of the combination plate is $50 \mathrm{ml} / \mathrm{min}$, and $100 \mathrm{ml} / \mathrm{min}$ comes to the large-scale cubic sample.

\section{Data Availability}

The data used to support the findings of this study are available from the corresponding author upon request.

\section{Conflicts of Interest}

The authors declare there are no conflicts of interest regarding the publication of this paper.

\section{Acknowledgments}

This work was supported by the National Science Foundation for Young Scientist of China (51904196) and the Major Science and Technology Special Project of Shanxi Province (20201102002-1), which are greatly acknowledged.

\section{References}

[1] Y. Liang, Y. Cheng, Q. Zou, W. Wang, Y. Ma, and Q. Li, "Response characteristics of coal subjected to hydraulic fracturing: an evaluation based on real-time monitoring of borehole strain and acoustic emission," Journal of Natural Gas Science and Engineering, vol. 38, pp. 402-411, 2017.

[2] J. Adachi, E. Siebrits, A. Peirce, and J. Desroches, "Computer simulation of hydraulic fractures," International Journal of
Rock Mechanics and Mining Sciences, vol. 44, no. 5, pp. 739-757, 2007.

[3] T. Shu, P. Zhejun, T. Shuling, and C. Shida, "Current status and geological conditions for the applicability of CBM drilling technologies in China: a review," International Journal of Coal Geology, vol. 202, pp. 95-108, 2019.

[4] J. Wang, R. Wu, and P. Zhang, "Characteristics and applications of gas desorption with excavation disturbances in coal mining," International Journal of Coal Science \& Technology, vol. 2, no. 1, pp. 30-37, 2015.

[5] Y. Jiang, H. Lian, V. phu Nguyen, and L. Weiguo, "Propagation behavior of hydraulic fracture across the coal-rock interface under different interfacial friction coefficients and a new prediction model," Journal of Natural Gas Science and Engineering, vol. 68, Article ID 102894, 2019.

[6] Z. Meng, J. Zhang, and R. Wang, "In-situ stress, pore pressure and stress-dependent permeability in the Southern Qinshui Basin," International Journal of Rock Mechanics and Mining Sciences, vol. 48, no. 1, pp. 122-131, 2011.

[7] Y. Wu, S. Tao, W. Tian, H. Chen, and S. Chen, "Advantageous seepage channel in coal seam and its effects on the distribution of high-yield areas in the fanzhuang CBM block, southern Qinshui Basin, China," Natural Resources Research, vol. 30, no. 3, pp. 2361-2376, 2021.

[8] Z. Liu, X. Ren, X. Lin, H. Lian, L. Yang, and J. Yang, "Effects of confining stresses, pre-crack inclination angles and injection rates: observations from large-scale true triaxial and hydraulic fracturing tests in laboratory," Rock Mechanics and Rock Engineering, vol. 53, no. 4, pp. 1991-2000, 2020.

[9] Z. Liu, S. Wang, H. Lian, and L. Yang, "Experimental study on the effects of pre-cracks, fracturing fluid, and rock mechanical characteristics on directional hydraulic fracturing with axial pre-cracks," Geomech. Geophys. Geo-energ. Geo-resour, vol. 7, no. 29, pp. 1-14, 2021.

[10] T. N. Olsen and G. Brenize, "Improvement processes for coalbed nature gas completion and stimulation," in Proceedings of the SPE 84122 presented at SPE Annual Technical Conference and Exhibition, Denvor, CO, USA, October 2003.

[11] T. N. Olsen and T. R. Bratton, "Application of indirect fracturing for efficient stimulation of coalbed methane," in Proceedings of the SPE 107985 presented at SPE Rocky Mountain Oil \& Gas Technology Symposium, Denvor, CO, USA, April 2007.

[12] X. Zeng and Y. Wei, "Crack deflection in brittle media with heterogeneous interfaces and its application in shale fracking," Journal of the Mechanics and Physics of Solids, vol. 101, pp. 235-249, 2017.

[13] W. Cao, B. Yildirim, S. Durucan et al., "Fracture behaviour and seismic response of naturally fractured coal subjected to true triaxial stresses and hydraulic fracturing," Fuel, vol. 288, Article ID 119618, 2021.

[14] J. Yang, H. Lian, and L. Li, "Fracturing in coals with different fluids: an experimental comparison between water, liquid $\mathrm{CO}_{2}$, and supercritical $\mathrm{CO}_{2}$," Scientific Reports, vol. 10, Article ID 18681, 2020.

[15] Y. S. Zou, S. C. Zhang, T. Zhou, and T. K. Guo, "Experimental investigation into hydraulic fracture network propagation in gas shales using CT scanning technology," Rock Mechanics and Rock Engineering, vol. 49, pp. 33-45, 2016.

[16] H. L. JianfengYang and L. Li, "Investigating the effect of confining pressure on fracture toughness of $\mathrm{CO}_{2}$-saturated coals," Engineering Fracture Mechanics, vol. 242, no. 4, Article ID 107496, 2021. 
[17] T. Wang, W. Hu, D. Elsworth et al., "The effect of natural fractures on hydraulic fracturing propagation in coal seams," Journal of Petroleum Science and Engineering, vol. 150, pp. 180-190, 2017.

[18] G. D. Anderson, "Effects of friction on hydraulic fracture growth near unbonded interfaces in Rocks," Society of Petroleum Engineers, vol. 21, no. 1, pp. 21-29, 1981.

[19] L. W. Teufel and J. A. Clark, "Hydraulic fracture propagation in layered rock: experimental studies of fracture containment," Society of Petroleum Engineers, vol. 24, no. 2, pp. 449-456, 1984.

[20] E. R. Simonson, A. S. Abou-Sayed, and R. J. Clifton, "Containment of massive hydraulic fractures," Society of Petroleum Engineers, vol. 18, no. 1, pp. 27-32, 1978.

[21] L. Defuel and J. Clark, "Hydraulic fracture propagation in layered rock: experimental studies of fracture containment," Society of Petroleum Engineers, vol. 24, no. 1, pp. 19-32, 1981.

[22] H. H. Abass, M. L. Van, and W. M. El, "Experimental observations of hydraulic fracture propagation through coal blocks," Society of Petroleum Engineers, vol. 2, no. 2, pp. 108-128, 1990.

[23] P. F. Wu, W. G. Liang, Z. G. Li, M. T. Cao, and J. F. Yang, "Investigations on mechanical properties and crack propagation characteristics of coal and sandy mudstone using three experimental methods," Rock Mechanics and Rock Engineering, vol. 50, no. 1, pp. 215-223, 2017.

[24] J. Yang, H. Lian, and V. Phu Nguyen, "Study of mixed mode I/ II cohesive zone models of different rank coals," Engineering Fracture Mechanics, vol. 246, no. 4, Article ID 107611, 2021.

[25] A. A. Griffith, "Phenomena of rupture and flow in solid," Philosophical Transactions of the Royal Society of London, Series A, vol. 221, pp. 163-198, 1920.

[26] S. Aoki, Simulation Analysis of Fracture with Debonding in Ceramic/Metal Joints, Springer, Berlin, Germany, 1995.

[27] G. C. Shi, Mechanics of Fracture, Noodhoof International Publication Leydon, NewYork, NY, USA, 1972. 